\title{
Exploring the Reactivity of a Frustrated Sn/P Lewis Pair: The Highly Selective Complexation of the cis-Azobenzene Photoisomer
}

\author{
Philipp Holtkamp, Dario Poier, Beate Neumann, Hans-Georg Stammler, and \\ Norbert W. Mitzel ${ }^{*[a]}$
}

\begin{abstract}
The reactivity of the geminal frustrated Lewis pair (FLP) $\left(\mathrm{F}_{5} \mathrm{C}_{2}\right)_{3} \mathrm{SnCH}_{2} \mathrm{P}(\mathrm{tBu})_{2}(1)$ was explored by reacting it with a variety of small molecules (PhOCN, PhNCS, PhCCH, tBuCCH, $\quad \mathrm{H}_{3} \mathrm{CC}(\mathrm{O}) \mathrm{CH}=\mathrm{CH}_{2}, \quad \mathrm{Ph}[\mathrm{C}(\mathrm{O})]_{2} \mathrm{Ph}, \quad \mathrm{PhN}=\mathrm{NPh}$ and $\mathrm{Me}_{3} \mathrm{SiCHN}_{2}$ ), featuring polar or non-polar multiple bonds and/or represent $\alpha, \beta$-unsaturated systems. While most adducts are formed readily, the binding of azobenzene requires UV-induced photoisomerization, which results in the highly
\end{abstract}

selective complexation of cis-azobenzene. In the case of benzil, the reaction does not lead to the expected 1,2- or 1,4-addition products, but to the non-stereoselective $(t \mathrm{Bu})_{2} \mathrm{PCH}_{2}$-transfer to a prochiral keto function of benzil. All adducts of 1 were characterised by means of multinuclear NMR spectroscopy, elemental analyses and X-ray diffraction experiments.

\section{Introduction}

With the discovery of metal-free reversible heterolytic hydrogen splitting in 2006, Stephan et al. laid the foundation for frustrated Lewis pair (FLP) chemistry. ${ }^{[1]}$ Just over a decade later, the concept of frustrated Lewis pairs has emerged as an important tool in main group chemistry for describing, predicting and exploring new pathways of reactions. ${ }^{[2]}$ Whereas Lewis' definition of acids and bases included the mutual neutralization of both by forming a stable adduct, ${ }^{[3]}$ the FLP concept describes the inhibition of adduct formation by steric shielding of acid and base while maintaining their reactivity potential. ${ }^{\text {[2a-f] }}$ This can be used for the activation of various unreactive small molecules, ${ }^{[2 a-f]}$ but also for capturing unstable species. ${ }^{[4]}$ Recent results show that even classical Lewis acid-base adducts can exhibit FLP reactivity. ${ }^{[5]}$ Typically, inter- or intramolecular combinations of group 13 Lewis acids $(B, A l)$ and group 15 Lewis bases $(N, P)$ serve as active FLP systems. ${ }^{[2 a-f, 6]}$ However, the

[a] Dr. P. Holtkamp, D. Poier, B. Neumann, Dr. H.-G. Stammler, Prof. Dr. N. W. Mitzel

Lehrstuhl für Anorganische Chemie und Strukturchemie

Fakultät für Chemie, Universität Bielefeld

Universitätsstraße 25, 33615 Bielefeld (Germany)

E-mail:mitzel@uni-bielefeld.de

$\square$ Supporting information and the ORCID identification number(s) for the

(iD) auth author(s) of this article can be found under: https://doi.org/10.1002/chem.202004600.

of (c) 2020 The Authors. Chemistry - A European Journal published by Wiley$\mathrm{VCH} \mathrm{GmbH}$. This is an open access article under the terms of the Creative Commons Attribution Non-Commercial NoDerivs License, which permits use and distribution in any medium, provided the original work is properly cited, the use is non-commercial and no modifications or adaptations are made. range of Lewis acidic functions is continuously being expanded to include group $14\left(\mathrm{Si}_{,}^{[7]} \mathrm{Ge}^{[7 a, 8]} \mathrm{Sn}^{[8,9]}\right)$ elements and rareearth ${ }^{[10]}$ or transition metals. ${ }^{[11]}$ Besides catalytic hydrogenation of unsaturated substrates ${ }^{[12]}$ and conversion of $\mathrm{CO}_{2}$ and $\mathrm{CO}$ into chemical feedstock, ${ }^{[2 a-f, 13]}$ the activation of dinitrogen is a major aspect of current FLP research. ${ }^{[14]}$ Due to the high $\mathrm{N} \equiv \mathrm{N}$ bond stability in dinitrogen and the associated high global energy consumption while converting dinitrogen to ammonia, the investigation of $\mathrm{N}_{2}$ containing compounds is of interest in order to gain knowledge for a long-term low-energy alternative to the Haber-Bosch process. ${ }^{[14 a]}$ Thus, Stephan and Melen consider the hydroboration of diazomethane derivatives as a promising step towards metal-free dinitrogen activation. ${ }^{[14]}$

Recent results from Stephan et al. show that azobenzene, featuring an $\mathrm{N}=\mathrm{N}$ double bond, is also suitable for use in FLP chemistry. They reported on the phosphinoboration of azobenzene by $\mathrm{Ph}_{2} \mathrm{PBcat}$ (cat=catecholate), yielding the PhNNPhlinked $\mathrm{B} / \mathrm{P}$-FLP $\mathrm{Ph}_{2} \mathrm{P}(\mathrm{NPh})_{2} \mathrm{Bcat}$. Such hydrazine-backbone-type FLPs were found to bind another equivalent of azobenzene via 1,2-addition, yielding six-membered heterocycles. ${ }^{[15]}$

Recently, we reported on the tetrel-based FLP systems $\left(\mathrm{F}_{5} \mathrm{C}_{2}\right)_{3} \mathrm{ECH}_{2} \mathrm{P}(t \mathrm{Bu})_{2}(\mathrm{E}=\mathrm{Si}, \mathrm{Ge}, \mathrm{Sn}(1))$. They differ significantly in their reactivities. ${ }^{[7, b, 9 a]}$ Of these, Sn/P-FLP $\left(\mathrm{F}_{5} \mathrm{C}_{2}\right)_{3} \mathrm{SnCH}_{2} \mathrm{P}(t \mathrm{Bu})_{2}$ (1), is capable of reversibly binding $\mathrm{CO}_{2}$ and turned out to be the most versatile FLP. ${ }^{[9]}$ Consequently, we set out to extend the scope with regard to binding nitrogen containing small molecules.

\section{Results and Discussion}

Reacting the Sn/P-FLP $\left(\mathrm{F}_{5} \mathrm{C}_{2}\right)_{3} \mathrm{SnCH}_{2} \mathrm{P}(t \mathrm{Bu})_{2}$ (1) with a mixture of cis- and trans-azobenzene in an NMR test reaction led to 


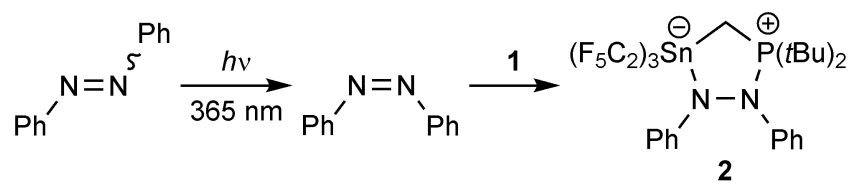

Scheme 1. UV-induced photoisomerization of azobenzene and its reaction with FLP 1.

nearly no conversion. This is probably due to the steric hindrance for the 1,2-addition of the trans-isomer, which is energetically favoured and more abundant under normal conditions. ${ }^{[16]}$ To prove this hypothesis, we attempted to use the known trans- into cis-conversion of azobenzenes via photoisomerization (Scheme 1) to produce the less hindered cis-isomer. After a total of five hours of UV irradiation $(\lambda=365 \mathrm{~nm})$, a complete conversion of FLP 1 was observed in the ${ }^{1} \mathrm{H}$ NMR spectrum (Figure 1). The immediate formation of the corresponding azobenzene adduct $\mathbf{2}$ was not only indicated by the disappearing signals of the starting materials, but also by the formation of eight characteristic adduct signals. Apart from the tert-butyl and methylene proton signals at 0.84 and $1.70 \mathrm{ppm}$, six resonances for two different phenyl groups were observed in the range of 6.55 to $7.40 \mathrm{ppm}$. Unexpectedly, a longer irradiation period led to decomposition of excess FLP $\mathbf{1}$ and adduct $\mathbf{2}$.

In a reaction on preparative scale, 1 was reacted with the isomeric mixture of azobenzene under UV irradiation $(\lambda=$ $365 \mathrm{~nm}$ ) for 5 hours and afforded the corresponding PhNNPh adduct $\mathbf{2}$ in $53 \%$ yield after work-up. The molecular structure of 2 (Figure 2) in the crystal exhibits an envelope-like fivemembered heterocycle with two exocyclic N-Ph units. Compared to the $\mathrm{N}-\mathrm{N}$ bond length (trans: $1.189 \AA_{1}^{[17]}$ cis: $\left.1.251 \AA^{[18]}\right)$ in azobenzene, the $\mathrm{N}-\mathrm{N}$ bond in adduct $\mathbf{2}$ is significantly longer with $1.446(3) \AA$. The sum of angles at $N(1)$ and $\mathrm{N}(2)$ are $358.6(6)^{\circ}$ and $357.9(6)^{\circ}$, respectively, indicating them to be nearly planar. A sum of angles for the equatorial groups of $360.0(3)^{\circ}$ and a $\tau_{\mathrm{Sn}}$ parameter of 0.78 (Table 1) indicate a slightly distorted trigonal bipyramidal coordination sphere at the tin atom. The latter is calculated by subtracting the two largest bond angles at $\mathrm{S} n$ and dividing the result by $60^{\circ}$.

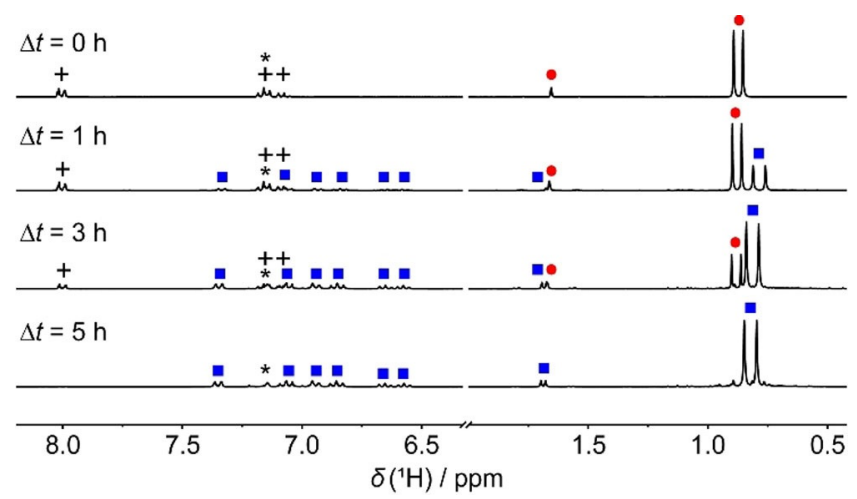

Figure 1. ${ }^{1} \mathrm{H}$ NMR spectra of a mixture of $1(\bullet)$ and cis/trans-azobenzene $(+)$ in $\mathrm{C}_{6} \mathrm{D}_{6}\left({ }^{*}\right)$ solution after different times $(\Delta t)$ of UV irradiation $(\lambda=365 \mathrm{~nm})$. Initially, no formation of adduct $\mathbf{2}$ ( $\square$ ) takes place, but it is complete after $5 \mathrm{~h}$.

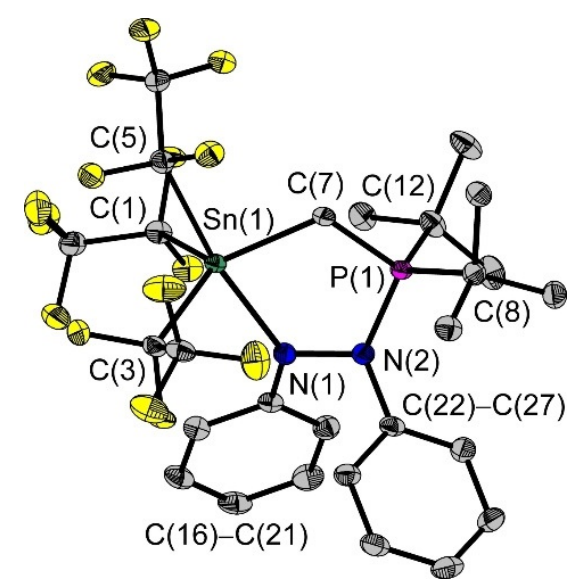

Figure 2. Molecular structure of compound $\mathbf{2}$ in the solid state. Ellipsoids are set at $50 \%$ probability; hydrogen atoms are omitted for clarity. Selected bond lengths $[\AA]$ and angles $\left[{ }^{\circ}\right]: P(1)-C(7) 1.785(3), P(1)-C(8) 1.879(3), P(1)-$ $\mathrm{N}(2) 1.668(3), \mathrm{Sn}(1)-\mathrm{N}(1) 2.199(2), \mathrm{Sn}(1)-C(1) 2.242(3), \mathrm{Sn}(1)-C(5) 2.360(3)$, $\mathrm{Sn}(1)-\mathrm{C}(7) 2.164(3), \mathrm{N}(1)-\mathrm{N}(2) 1.446(3), \mathrm{C}(16)-\mathrm{N}(1) 1.403(4), \mathrm{C}(22)-\mathrm{N}(2)$ 1.432(4); $\mathrm{P}(1)-\mathrm{C}(7)-\mathrm{Sn}(1)$ 112.7(2), $\mathrm{C}(7)-\mathrm{P}(1)-\mathrm{N}(2)$ 103.8(1), $\mathrm{P}(1)-\mathrm{N}(2)-\mathrm{N}(1)$ 116.2(2), $\mathrm{P}(1)-\mathrm{N}(2)-\mathrm{C}(22)$ 126.8(2), C(22)-N(2)-N(1) 114.9(2), Sn(1)-N(1)-N(2) 115.3(2), C(16)-N(1)-N(2) 112.9(2), C(16)-N(1)-Sn(1) 130.4(2), N(1)-Sn(1)-C(1) $95.4(1), \mathrm{N}(1)-\mathrm{Sn}(1)-\mathrm{C}(5)$ 168.5(1), N(1)-Sn(1)-C(7) 83.0(1).

\begin{tabular}{|c|c|c|c|c|c|}
\hline Comp. & $\delta\left({ }^{31} \mathrm{P}\right)[\mathrm{ppm}]^{[\mathrm{a}]}$ & $\delta\left({ }^{119} \mathrm{Sn}\right)[\mathrm{ppm}]^{[\mathrm{a}]}$ & ${ }^{2} J_{\mathrm{Sn}, \mathrm{P}}[\mathrm{Hz}]^{[\mathrm{a}]}$ & $\Varangle(\mathrm{Sn}-\mathrm{C}-\mathrm{P})\left[{ }^{\circ}\right]$ & $\tau_{\mathrm{Sn}}{ }^{[\mathrm{b}]}$ \\
\hline 2 & 77.2 & -348.5 & 70 & $112.7(2)$ & 0.78 \\
\hline 3 & 58.9 & -318.8 & 77 & $96.2(1)$ & 0.56 \\
\hline 4 & 35.3 & -273.2 & 68 & $110.3(3)$ & 0.77 \\
\hline 5 & 31.5 & -274.4 & 64 & $117.2(1)$ & 0.74 \\
\hline 6 & 49.1 & -268.5 & 77 & $111.4(1)$ & 0.79 \\
\hline 7 & 60.5 & -275.8 & 105 & $110.1(3)$ & 0.22 \\
\hline 8 & 53.4 & ${ }^{[c]}$ & $-[c]$ & $122.2(1)$ & 0.76 \\
\hline 9 & 8.5 & -397.4 & - & - & - \\
\hline
\end{tabular}

[a] In $\mathrm{C}_{6} \mathrm{D}_{6}$ at ambient temperature. [b] Calculated for pentacoordinated Sn according to Addison et al. ${ }^{[19]}$ [c] Not detectable due to poor solubility.

$\tau_{\text {Sn }}$ parameters close to 1 indicate a trigonal bipyramidal coordination sphere while those close to 0 indicate a square pyramidal one. ${ }^{[19]}$ Compared to the equatorial $\mathrm{Sn}-\mathrm{C}$ bonds $(2.164(3)-2.257(3) \AA$ ) the axial $S n(1)-C(5)$ bond is longer (2.360(3) $\AA)$. The ${ }^{31} \mathrm{P}$ and ${ }^{119} \mathrm{Sn}$ NMR chemical shifts of $\mathbf{2}$ are 77.2 and -348.5 ppm (Table 1).

In contrast to azobenzene, diazomethane derivatives feature terminal $\mathrm{N}_{2}$ moieties; they have recently been discussed as a pre-stage towards metal-free dinitrogen activation. ${ }^{[14]}$ Differences in their reaction behaviour are illustrated when 1 is reacted with trimethylsilyldiazomethane $\left(\mathrm{Me}_{3} \mathrm{SiCHN}_{2}\right)$. In analogy to the related $\left(\mathrm{F}_{5} \mathrm{C}_{2}\right)_{3} \mathrm{SiCH}_{2} \mathrm{P}(t \mathrm{Bu})_{2}{ }^{[\mathrm{ra}, \mathrm{b}]}$ conversion of FLP 1 with $\mathrm{Me}_{3} \mathrm{SiCHN}$ provides 1,1 -adduct 3 in quantitative yields. The molecular structure of $\mathbf{3}$ in the solid contains a four-membered NSnCP-heterocycle (Figure 3) involving only the terminal nitrogen atom of $\mathrm{Me}_{3} \mathrm{SiCHN}_{2}$. Thus, binding $\mathrm{Me}_{3} \mathrm{SiCHN}_{2}$ results in a narrowed angle $\mathrm{Sn}(1)-\mathrm{C}(7)-\mathrm{P}(1)$ of $96.2(1)^{\circ}$ compared to 2 $\left(112.7(1)^{\circ}\right)$. The angles $\mathrm{C}(5)-\mathrm{Sn}(1)-\mathrm{N}(1)\left(161.6(1)^{\circ}\right)$ and $\mathrm{C}_{\mathrm{eq}}-\mathrm{Sn}(1)-$ $\mathrm{N}(1)\left(69.6(1)^{\circ}-96.6(1)^{\circ}\right)$ as well as a $\tau_{\mathrm{Sn}}$ parameter of 0.56 indi- 


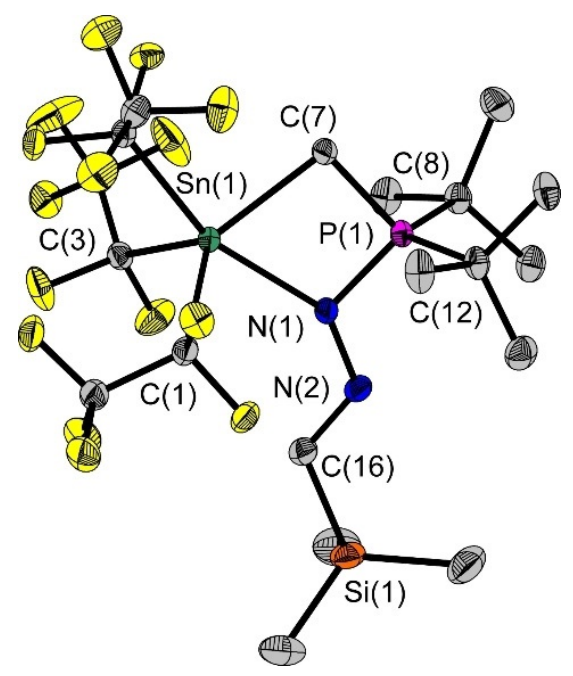

Figure 3. Molecular structure of compound $\mathbf{3}$ in the solid state. Ellipsoids are set at $50 \%$ probability; hydrogen atoms are omitted for clarity. Selected bond lengths $[\AA]$ and angles $\left[{ }^{\circ}\right]$ : $P(1)-C(7) 1.780(2), P(1)-C(8) 1.852(2), P(1)-$ $\mathrm{N}(1)$ 1.653(2), Sn(1)-N(1) 2.251(2), Sn(1)-C(1) 2.243(2), Sn(1)-C(5) 2.294(2), $\mathrm{Sn}(1)-\mathrm{C}(7) 2.196(2), \mathrm{N}(1)-\mathrm{N}(2)$ 1.393(2), C(16)-N(2) 1.279(2), C(16)-Si(1) 1.875(2); $\mathrm{P}(1)-\mathrm{C}(7)-\mathrm{Sn}(1)$ 96.2(1), C(7)-P(1)-N(1) 95.3(1), $\mathrm{P}(1)-\mathrm{N}(1)-\mathrm{N}(2)$ 115.4(1), $\mathrm{P}(1)-\mathrm{N}(1)-\mathrm{Sn}(1)$ 98.0(1), Sn(1)-N(1)-N(2) 146.6(1), N(1)-Sn(1)-C(1) 90.9(1), N(1)$\mathrm{Sn}(1)-C(5)$ 161.6(1), N(1)-Sn(1)-C(7) 69.6(1).

cate a clearly distorted trigonal bipyramidal coordination sphere at the tin atom (Table 1). The $\mathrm{N}-\mathrm{N}$ bond in $\mathbf{3}$ is slightly shorter than a typical $\mathrm{N}-\mathrm{N}$ single bond and than that in 2 ; it is probably due to the hydrazine-type structure, that is, one nitrogen atom bonded to a three-coordinate carbon atom.

In addition to the investigation of the $\mathrm{N}_{2}$-functional azo compounds PhNNPh and $\mathrm{Me}_{3} \mathrm{SiCHN}_{2}$, the examination of $\mathrm{C} \equiv \mathrm{X}$ triple bond systems $(X=C, N)$ is of particular interest, as they are isosteric to dinitrogen, although of course more polar and easier to dissociate than $\mathrm{N}_{2}$. The reaction of 1 with nitrile derivatives, such as benzonitrile and pivalonitrile does neither result in adduct formation nor in $\mathrm{R}-\mathrm{CN}$...Sn coordination $(\mathrm{R}=\mathrm{Ph}$, $t \mathrm{Bu})$, as was concluded from the absence of changes in the NMR resonances of 1 . In contrast, the reaction of 1 with phenyl cyanate PhOCN ( $\mathrm{R}=\mathrm{OPh}$; Scheme 2 ) surprisingly proceeded under 1,2-addition to the $\mathrm{C}-\mathrm{N}$ bond affording adduct 4 in $44 \%$ yield. Since crystals of 4 show a phase transition at $100 \mathrm{~K}$, data for X-ray diffraction were recorded at $200 \mathrm{~K}$. The molecular structure of $\mathbf{4}$ (Figure 4 ) in the crystal displays a fivemembered heterocycle with a $\mathrm{N}(1)-\mathrm{C}(16)$ double bond of $1.227(6) \AA$ and an exocyclic C-O-Ph unit. The $\mathrm{Sn}(1)-\mathrm{C}(7)-\mathrm{P}(1)$

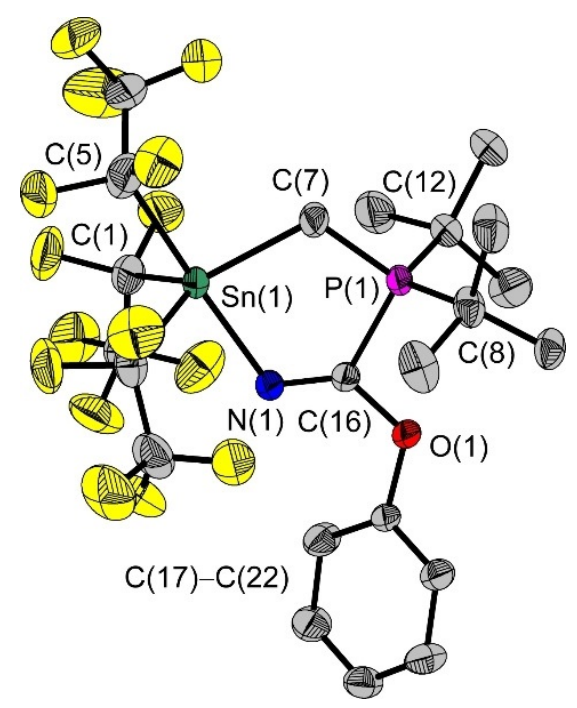

Figure 4. Molecular structure of compound $\mathbf{4}$ in the solid state. Ellipsoids are set at $30 \%$ probability; hydrogen atoms are omitted for clarity. Selected bond lengths $[\AA]$ and angles $\left[{ }^{\circ}\right]: P(1)-C(7) 1.772(5), P(1)-C(8) 1.862(6), P(1)-$ $\mathrm{C}(16)$ 1.869(5), Sn(1)-N(1) 2.155(4), Sn(1)-C(1) 2.233(7), Sn(1)-C(5) 2.313(8), $\mathrm{Sn}(1)-C(7) 2.202(5), \mathrm{O}(1)-C(16) 1.375(6), \mathrm{N}(1)-C(16) 1.227(7) ; \mathrm{P}(1)-C(7)-S n(1)$ 110.3(3), $C(7)-P(1)-C(16)$ 101.4(2), O(1)-C(16)-P(1) 107.2(3), N(1)-C(16)-P(1) 124.0(4), N(1)-C(16)-O(1) 128.8(4), C(16)-N(1)-Sn(1) 117.0(3), N(1)-Sn(1)-C(1) 91.2(2), N(1)-Sn(1)-C(5) 171.7(2), N(1)-Sn(1)-C(7) 86.9(2).

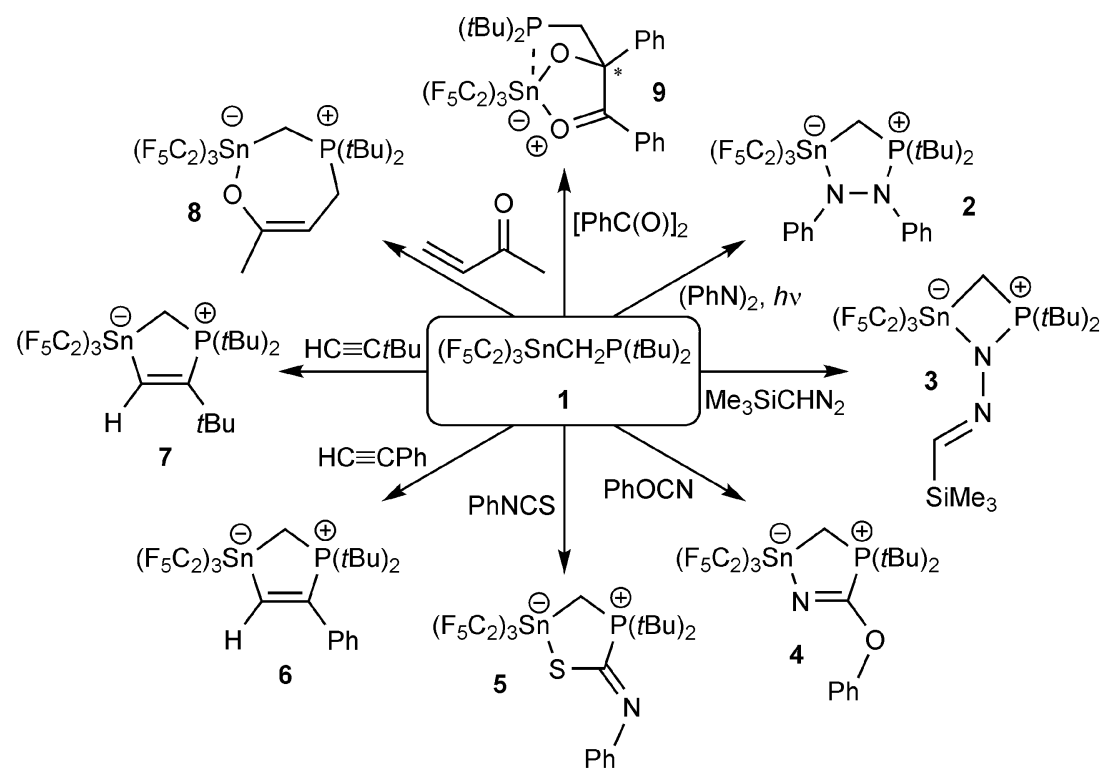

Scheme 2. Reactions of FLP 1 with selected substrates at ambient temperature. 
angle of $110.3(3)^{\circ}$ matches the angle of the corresponding constitutional isomeric phenyl isocyanate adduct $\left(110.7(1)^{\circ[9 a]}\right)$. Compound 4 shows a slightly distorted trigonal bipyramidal coordination at the tin atom, indicated by a $\tau_{\mathrm{sn}}$ parameter of 0.77 (Table 1).

Less surprisingly, no addition to the $\mathrm{C}-\mathrm{N}$ but to the $\mathrm{C}-\mathrm{S}$ bond was found, when reacting 1 with the heterocumulene homologue phenyl isothiocyanate PhNCS by forming adduct 5 in $79 \%$ yield. The molecular structure of $\mathbf{5}$ reveals an envelope-like CSSnCP-heterocycle (Figure 5) and a C-S bond, which are well comparable to the related $\mathrm{CS}_{2}$ adduct, and agrees well with expectations from the HSAB concept. ${ }^{[9 a, 20]}$ Compared to the corresponding PhOCN adduct 4, compound 5 has a slightly widened $S n(1)-C(7)-P(1)$ angle of $117.2(1)^{\circ}$, close to that of the related $\mathrm{CS}_{2}$ adduct $\left(118.4(1)^{\circ[9 a]}\right)$. In addition, the molecular structure of $\mathbf{5}$ shows a slightly more distorted trigonal bipyramidally coordinate tin atom $\left(\tau_{\mathrm{Sn}}=0.74\right.$, Table 1$)$. With a chemical shift of $164.3 \mathrm{ppm}$, the ${ }^{13} \mathrm{C}$ NMR signal of the SC(NPh) unit is between those of the $\mathrm{C}=\mathrm{X}$ moieties $(\mathrm{X}=\mathrm{S}, \mathrm{NPh})$ in the corresponding $\mathrm{CS}_{2}$ and PhOCN adducts with 226.8 and $150.0 \mathrm{ppm}$, respectively. ${ }^{[9 a]}$

In addition, selective addition to less polar triple bond systems was observed when reacting 1 with terminal alkynes of the type $\mathrm{HC} \equiv \mathrm{CR}(\mathrm{R}=\mathrm{Ph}, t \mathrm{Bu}$; Scheme 2$)$. In both cases, fivemembered SnCPCC heterocycles, with the incorporated $C-R$ unit $(\mathrm{R}=\mathrm{Ph}, t \mathrm{Bu})$ each being bound by the phosphorus atom (Figure 6/Figure 7), were obtained as adducts. This proves that FLP 1 is capable of reacting with substrates of relatively low polarity. X-ray diffraction analysis provided nearly similar values for the $\operatorname{Sn}(1)-C(7)-P(1)$ bond angles $\left(111.4(1)^{\circ} / 110.1(3)^{\circ}\right)$ and the $C(16)-C(17)$ bond lengths (1.339(4) $\AA / 1.336(7) \AA$ ) of both. These $\mathrm{C}-\mathrm{C}$ bond lengths are typical lengths of $\mathrm{C}=\mathrm{C}$ double bonds. However, a significant structural difference is observed in the coordination geometry of the tin atom. While a $\tau_{\text {Sn }}$ parameter of 0.79 indicates a slightly distorted trigonal bipyrami-

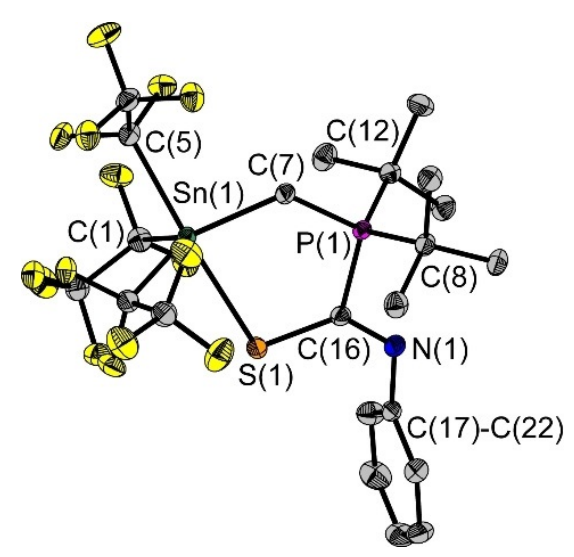

Figure 5. Molecular structure of compound $\mathbf{5}$ in the solid state. Ellipsoids are set at $50 \%$ probability; hydrogen atoms are omitted for clarity. Selected bond lengths $[\AA]$ and angles $\left[^{\circ}\right]$ : $\mathrm{P}(1)-C(7)$ 1.782(2), $\mathrm{P}(1)-\mathrm{C}(8)$ 1.858(2), $\mathrm{P}(1)-$ $C(16) 1.845(2), S n(1)-S(1) 2.618(1), S n(1)-C(1) 2.263(2), S n(1)-C(5)$ 2.294(2), $S n(1)-C(7) 2.177(2), S(1)-C(16) 1.730(2), N(1)-C(16) 1.276(3) ; P(1)-C(7)-S n(1)$ 117.2(1), C(7)-P(1)-C(16) 108.5(1), S(1)-C(16)-P(1) 120.7(1), N(1)-C(16)-P(1) 111.2(2), N(1)-C(16)-S(1) 128.0(2), C(16)-S(1)-Sn(1) 101.8(1), S(1)-Sn(1)-C(1) 87.1(1), S(1)-Sn(1)-C(5) 173.8(1), S(1)-Sn(1)-C(7) 86.4(1).

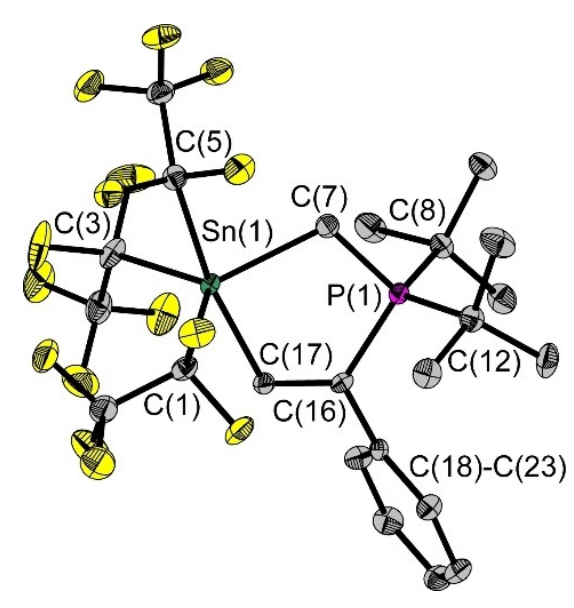

Figure 6. Molecular structure of compound 6 in the solid state. Ellipsoids are set at $50 \%$ probability; hydrogen atoms are omitted for clarity. Selected bond lengths $[\AA]$ and angles $\left[{ }^{\circ}\right]$ : $P(1)-C(7) 1.779(3), P(1)-C(8) 1.861(3), P(1)-$ $C(12) 1.865(3), P(1)-C(16) 1.833(2), S n(1)-C(1) 2.256(3), S n(1)-C(3) 2.226(5)$, $S n(1)-C(5) 2.346(3), S n(1)-C(7) 2.198(3), S n(1)-C(17) 2.207(3), C(16)-C(17)$ 1.339(4); $P(1)-C(7)-S n(1)$ 111.4(1), $C(7)-P(1)-C(16)$ 105.8(1), $C(17)-C(16)-P(1)$ 116.4(2), $C(17)-C(16)-C(18)$ 121.1(2), $C(18)-C(16)-P(1)$ 122.4(2), $C(16)-C(17)-$ $\mathrm{Sn}(1) 120.7(2), C(17)-S n(1)-C(1) 90.7(1), C(17)-S n(1)-C(3) 97.7(1), C(17)-S n(1)-$ $C(5) 170.2(1), C(17)-S n(1)-C(7) 84.5(1)$.

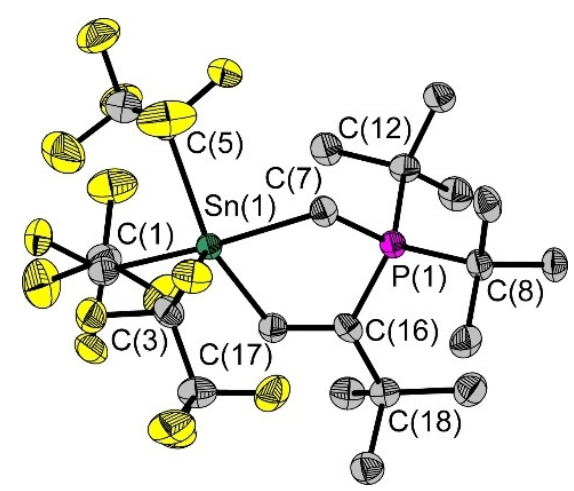

Figure 7. Molecular structure of compound $\mathbf{7}$ in the solid state. Ellipsoids are set at $50 \%$ probability; hydrogen atoms are omitted for clarity. Selected bond lengths $[\AA]$ and angles $\left[{ }^{\circ}\right]: P(1)-C(7) 1.776(5), P(1)-C(8) 1.884(5), P(1)-$ $C(12)$ 1.871(5), $P(1)-C(16)$ 1.859(5), Sn(1)-C(1) 2.305(6), Sn(1)-C(3) 2.234(5), $S n(1)-C(5) 2.307(5), S n(1)-C(7) 2.226(5), S n(1)-C(17) 2.163(5), C(16)-C(17)$ 1.336(7); $P(1)-C(7)-S n(1)$ 110.1(3), C(7)-P(1)-C(16) 104.3(2), C(17)-C(16)-P(1) 112.3(4), $C(17)-C(16)-C(18) 117.9(5), C(18)-C(16)-P(1)$ 129.7(4), $C(16)-C(17)-$ Sn(1) 125.1(4), C(17)-Sn(1)-C(1) 90.2(2), C(17)-Sn(1)-C(3) 104.1(2), C(17)-Sn(1)$C(5) 149.2(2), C(17)-S n(1)-C(7) 82.3(2)$.

dal coordination sphere in HCCPh adduct 6 , a $\tau_{\mathrm{Sn}}$ parameter of 0.22 reveals a square pyramidal one in $\mathrm{HCCtBu}$ adduct 7 (Table 1).

Furthermore, in order to investigate whether adduct formation proceeds via 1,2- or 1,4-addition when reacting 1 with $\alpha, \beta$-unsaturated carbonyl compounds, 1 was reacted with methyl vinyl ketone and benzil. In the case of conversion with methyl vinyl ketone the corresponding 1,4-addition product was obtained in $77 \%$ yield in the absence of light (in order to prevent methyl vinyl ketone from light-induced polymerization). The molecular structure of $\mathbf{8}$ (Figure 8) reveals a seven-membered heterocycle with exocyclic methyl group, 


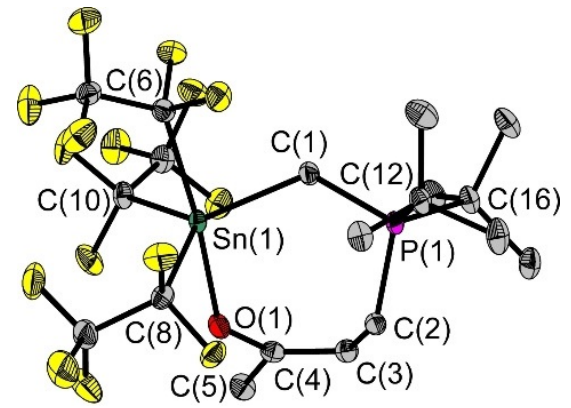

Figure 8. Molecular structure of compound $\mathbf{8}$ in the solid state. Ellipsoids are set at $50 \%$ probability; hydrogen atoms are omitted for clarity. Selected bond lengths $[\AA]$ and angles $\left[{ }^{\circ}\right]$ : $\mathrm{P}(1)-C(1) 1.801(2), \mathrm{P}(1)-\mathrm{C}(2) 1.820(2), \mathrm{P}(1)-$ $C(12) 1.866(2), P(1)-C(16) 1.878(2), S n(1)-C(1) 2.185(2), S n(1)-C(6) 2.331(2)$, $\mathrm{Sn}(1)-C(8)$ 2.248(2), $\mathrm{Sn}(1)-C(10) 2.252(2), \mathrm{Sn}(1)-\mathrm{O}(1) 2.086(2), \mathrm{O}(1)-C(4)$ 1.345(2), $C(3)-C(4)$ 1.347(3); $P(1)-C(1)-S n(1)$ 122.2(1), $C(1)-P(1)-C(2)$ 107.8(1), $\mathrm{O}(1)-\mathrm{Sn}(1)-\mathrm{C}(1)$ 96.0(1), O(1)-Sn(1)-C(6) 173.6(1), O(1)-Sn(1)-C(8) 80.6(1), O(1)$\operatorname{Sn}(1)-C(10) 87.6(1)$.

comparable to those described by Uhl and co-workers. ${ }^{[21]}$ They assume that the favoured 1,4-adduct formation of their geminal Al/P FLP with acrolein derivatives is due to the initiating Al...O-interaction under activation of the $C_{\beta}$ atom of the vinylcarbonyl moiety. ${ }^{[21]}$ Compared to the previously described fourand five-membered ring systems $2-7$, the $S n(1)-C(1)-P(1)$ angle in 8 is significantly expanded with $122.2(1)^{\circ}$.

In contrast to that, the reaction of FLP 1 with benzil, $\mathrm{PhC}(\mathrm{O})$ $\mathrm{C}(\mathrm{O}) \mathrm{Ph}$, did neither lead to the expected 1,2- nor 1,4-addition product, but to the formation of the racemic compound $\mathbf{9}$. Racemate $\mathbf{9}$ crystallizes as a two-component perfect inversion twin with two different molecules in the asymmetric unit. The molecular structure of $\mathbf{9}$ (Figure 9) reveals a non-stereoselective transfer of the $(t \mathrm{Bu})_{2} \mathrm{PCH}_{2}$ unit to one prochiral keto function of the prior benzil. This results in coordination of the tin atom

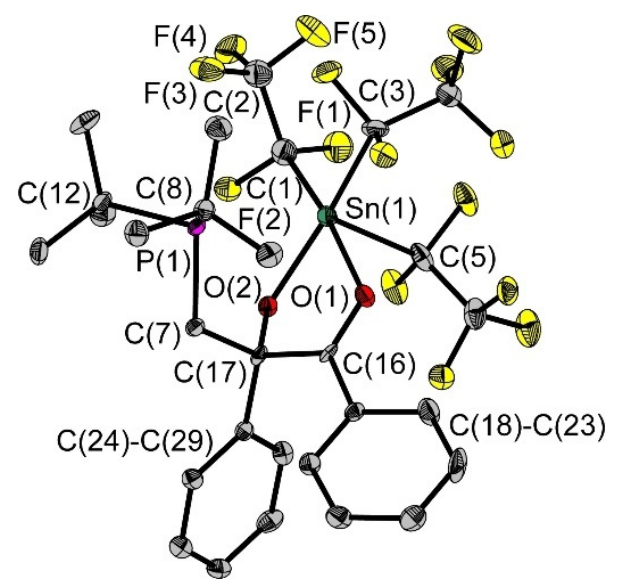

Figure 9. Molecular structure of the (S)-isomer of compound 9 in the solid state. Ellipsoids are set at $50 \%$ probability; hydrogen atoms are omitted for clarity. Selected bond lengths $[\AA]$ and angles $\left[{ }^{\circ}\right]$ : $\mathrm{P}(1)-\mathrm{C}(7) 1.850(5), \mathrm{P}(1)-\mathrm{C}(8)$ 1.895(5), $\mathrm{P}(1)-\mathrm{C}(12)$ 1.896(5), O(1)-C(16) 1.238(6), O(2)-C(17) 1.415(6), Sn(1)$\mathrm{O}(1)$ 2.254(4), Sn(1)-O(2) 2.005(4), Sn(1)-C(1) 2.294(6), Sn(1)-C(3) 2.270(6), $\mathrm{Sn}(1)-\mathrm{C}(5)$ 2.263(6); O(1)-Sn(1)-O(2) 75.2(1), O(1)-Sn(1)-C(1) 170.4(2), O(1)$\mathrm{Sn}(1)-\mathrm{C}(3)$ 85.4(2), O(1)-Sn(1)-C(5) 86.1(2), O(2)-Sn(1)-C(1) 96.2(2), O(2)-Sn(1)$\mathrm{C}(3)$ 152.2(2), O(2)-Sn(1)-C(5) 93.3(2), C(1)-Sn(1)-C(3) 104.1(2), C(1)-Sn(1)-C(5) 90.2(2), C(3)-Sn(1)-C(5) 105.1(2). through the formed alcoholate and the intact keto function. While the $\mathrm{Sn}(1)-\mathrm{O}(2)$ and $\mathrm{Sn}(2)-\mathrm{O}(4)$ bond lengths are given as 2.005(4) and 2.027(4) $\AA$, the $\mathrm{Sn}(1)-\mathrm{O}(1)$ and $\mathrm{Sn}(2)-\mathrm{O}(3)$ bonds are elongated correspondingly with 2.254(4) and 2.248(4) $\AA$, respectively. In addition, weak intramolecular Sn...P interactions are indicated by Sn...P distances of 3.058(1) and 2.992(1) $\AA$. This results in an almost octahedral coordination sphere for the tin atom. In solution, the ${ }^{119} \mathrm{Sn} \mathrm{NMR}$ signal is observed at $-397.4 \mathrm{ppm}$, while the ${ }^{31} \mathrm{P}$ NMR resonance is shifted to high field at $8.5 \mathrm{ppm}$. Furthermore, a chemical inequivalence of the methylene and tert-butyl protons ensues from the newly formed stereo centre. Thus, the diastereotopic protons of the methylene unit are found at 2.98 and 2.36 ppm with a geminal coupling constant of $15 \mathrm{~Hz}$.

\section{Conclusions}

In summary, we have extended the scope of the recently presented Sn/P FLP 1 regarding its ability of binding small molecules ( $\mathrm{PhN}=\mathrm{NPh}, \mathrm{Me}_{3} \mathrm{SiCHN}_{2}, \mathrm{PhOCN}$ and PhNCS) containing $\mathrm{N} \equiv \mathrm{C}$ and $\mathrm{N}=\mathrm{X}(\mathrm{X}=\mathrm{C}, \mathrm{S}, \mathrm{N})$ functions. In case of azobenzene UV-induced photoisomerization of the isomeric species enabled the highly selective complexation of cis-azobenzene. In addition, adduct formation towards less polar $\mathrm{C} \equiv \mathrm{C}$ triple bonds ( $\mathrm{HCCPh}, \mathrm{HCCtBu})$ and $\alpha, \beta$-unsaturated carbonyl compounds $\left(\mathrm{H}_{3} \mathrm{CC}(\mathrm{O}) \mathrm{CH}=\mathrm{CH}_{2}, \mathrm{Ph}[\mathrm{C}(\mathrm{O})]_{2} \mathrm{Ph}\right)$ was verified, wherein conversion of 1 with benzil resulted in the non-stereoselective transfer of the $(t B u)_{2} \mathrm{PCH}_{2}$ unit to benzil. The obtained results underline the diversity and reactivity of the presented Sn/P FLP 1, assign its value and encourage us to further investigate this class of compounds in future work.

\section{Experimental Section}

\section{Crystallographic data}

Deposition numbers 2025718, 2025719, 2025720, 2025721, 2025722, 2025723, 2025724, and 2025725 contain the supplementary crystallographic data for this paper. These data are provided free of charge by the joint Cambridge Crystallographic Data Centre and Fachinformationszentrum Karlsruhe Access Structures service.

\section{Acknowledgements}

We thank Felix Friedrich and Erik Stratmann for lab assistance, Marco Wissbrock for recording NMR spectra and Barbara Teichner for performing elemental analyses. We gratefully acknowledge financial support from Deutsche Forschungsgemeinschaft (DFG, grant Mi477/31-1 project no. 320753677). Open access funding enabled and organized by Projekt DEAL.

\section{Conflict of interest}

The authors declare no conflict of interest. 
Keywords: activation - fluoroalkyl groups - frustrated Lewis pairs $\cdot$ small molecules $\cdot$ tin

[1] G. C. Welch, R. R. San Juan, J. D. Masuda, D. W. Stephan, Science 2006 314, 1124-1126.

[2] a) D. W. Stephan, Science 2016, 354, aaf7229; b) D. W. Stephan, Acc Chem. Res. 2015, 48, 306-316; c) D. W. Stephan, G. Erker, Angew. Chem. Int. Ed. 2015, 54, 6400-6441; Angew. Chem. 2015, 127, 6498-6541; d) D. W. Stephan, G. Erker, Chem. Sci. 2014, 5, 2625-2641; e) D. W. Stephan, G. Erker, Angew. Chem. Int. Ed. 2010, 49, 46-76; Angew. Chem. 2010, 122, 50-81; f) D. W. Stephan, Dalton Trans. 2009, 3129-3136 g) C. M. Mömming, E. Otten, G. Kehr, R. Fröhlich, S. Grimme, D. W. Stephan, G. Erker, Angew. Chem. Int. Ed. 2009, 48, 6643-6646; Angew. Chem. 2009, 121, 6770-6773; h) P. Spies, G. Erker, G. Kehr, K. Bergander, R. Fröhlich, S. Grimme, D. W. Stephan, Chem. Commun. 2007, 50725074 ; i) G. C. Welch, D. W. Stephan, J. Am. Chem. Soc. 2007, 129, 1880 1881.

[3] G. N. Lewis, Valence and the Structure of Atoms and Molecules, The Chemical Catalog Company, Inc., New York, 1923.

[4] a) L. E. Longobardi, V. Wolter, D. W. Stephan, Angew. Chem. Int. Ed. 2015, 54, 809-812; Angew. Chem. 2015, 127, 823-826; b) M. W. P. Bebbington, S. Bontemps, G. Bouhadir, D. Bourissou, Angew. Chem. Int. Ed. 2007, 46, 3333-3336; Angew. Chem. 2007, 119, 3397-3400; c) A. Stute, L. Heletta, R. Fröhlich, C. G. Daniliuc, G. Kehr, G. Erker, Chem. Commun. 2012 48, 11739-11741; d) D. Pleschka, M. Layh, F. Rogel, W. Uhl, Philos. Trans. R. Soc. A 2017, 375, 20170011; e) D. H. A. Boom, A. R. Jupp, M. Nieger, A. W. Ehlers, J. C. Slootweg, Chem. Eur. J. 2019, 25, 13299-13308.

[5] T. C. Johnstone, G. N. J. H. Wee, D. W. Stephan, Angew. Chem. Int. Ed. 2018, 57, 5881 - 5884; Angew. Chem. 2018, 130, 5983-5986.

[6] a) C. Appelt, H. Westenberg, F. Bertini, A. W. Ehlers, J. C. Slootweg, K Lammertsma, W. Uhl, Angew. Chem. Int. Ed. 2011, 50, 3925-3928; Angew. Chem. 2011, 123, $4011-4014$; b) L. A. Körte, S. Blomeyer, S. Heidemeyer, A. Mix, B. Neumann, N. W. Mitzel, Chem. Commun. 2016, 52, 9949-9952

[7] a) T. A. Kinder, R. Pior, S. Blomeyer, B. Neumann, H.-G. Stammler, N. W. Mitzel, Chem. Eur. J. 2019, 25, 5899-5903; b) B. Waerder, M. Pieper, L. A Körte, T. A. Kinder, A. Mix, B. Neumann, H.-G. Stammler, N. W. Mitzel, Angew. Chem. Int. Ed. 2015, 54, 13416-13419; Angew. Chem. 2015, 127 13614-13617; c) T. A. Kinder, S. Blomeyer, M. Franke, F. Depenbrock, B. Neumann, H.-G. Stammler, N. W. Mitzel, Eur. J. Inorg. Chem. 2019, 3933 3939; d) T. J. Herrington, B. J. Ward, L. R. Doyle, J. McDermott, A. J. P. White, P. A. Hunt, A. E. Ashley, Chem. Commun. 2014, 50, 12753-12756; e) A. Schäfer, M. Reißmann, A. Schäfer, W. Saak, D. Haase, T. Müller Angew. Chem. Int. Ed. 2011, 50, 12636-12638; Angew. Chem. 2011, 123, 12845-12848; f) S. A. Weicker, D. W. Stephan, Chem. Eur. J. 2015, 21, $13027-13034$

[8] Y. Yu, J. Li, W. Liu, Q. Ye, H. Zhu, Dalton Trans. 2016, 45, 6259-6268.

[9] a) P. Holtkamp, F. Friedrich, E. Stratmann, A. Mix, B. Neumann, H.-G. Stammler, N. W. Mitzel, Angew. Chem. Int. Ed. 2019, 58, 5114-5118; Angew. Chem. 2019, 131, 5168-5172; b) S. Freitag, J. Henning, H. Schubert, L. Wesemann, Angew. Chem. Int. Ed. 2013, 52, 5640-5643; Angew. Chem. 2013, 125, 5750-5754; c) S. Freitag, K. M. Krebs, J. Henning, J.
Hirdler, H. Schubert, L. Wesemann, Organometallics 2013, 32, 6785 6791 ; d) K. M. Krebs, S. Freitag, H. Schubert, B. Gerke, R. Pöttgen, L. Wesemann, Chem. Eur. J. 2015, 21, 4628-4638; e) D. J. Scott, N. A. Phillips, J. S. Sapsford, A. C. Deacy, M. J. Fuchter, A. E. Ashley, Angew. Chem. Int. Ed. 2016, 55, 14738-14742; Angew. Chem. 2016, 128, 14958-14962 f) R. C. Turnell-Ritson, J. S. Sapsford, R. T. Cooper, S. S. Lee, T. Földes, P. A. Hunt, I. Pápai, A. E. Ashley, Chem. Sci. 2018, 9, 8716-8722; g) D. A. Dickie, E. N. Coker, R. A. Kemp, Inorg. Chem. 2011, 50, 11288-11290.

[10] M. Pieper, J.-H. Lamm, B. Neumann, H.-G. Stammler, N. W. Mitzel, Dalton Trans. 2017, 46, 5326-5336.

[11] a) M. Pieper, P. Auer, S. Schwarzbich, F. Kühn, B. Neumann, H.-G. Stammler, N. W. Mitzel, Z. Anorg. Allg. Chem. 2017, 643, 909-915; b) X. Xu, G. Kehr, C. G. Daniliuc, G. Erker, J. Am. Chem. Soc. 2013, 135, 6465-6476; c) A. M. Chapman, M. F. Haddow, D. F. Wass, J. Am. Chem. Soc. 2011, 133, 8826-8829; d) A. M. Chapman, M. F. Haddow, D. F. Wass, J. Am. Chem. Soc. 2011, 133, 18463-18478; e) R. Dobrovetsky, D. W. Stephan, Isr. J. Chem. 2015, 55, 206-209; f) R. Dobrovetsky, D. W. Stephan, Angew. Chem. Int. Ed. 2013, 52, 2516-2519; Angew. Chem. 2013, 125, 25762579; g) P. Jochmann, D. W. Stephan, Angew. Chem. Int. Ed. 2013, 52, 9831-9835; Angew. Chem. 2013, 125, 10014-10018; h) K. Chang, X. Wang, Z. Fan, X. Xu, Inorg. Chem. 2018, 57, 8568-8580.

[12] a) P. A. Chase, G. C. Welch, T. Jurca, D. W. Stephan, Angew. Chem. Int. Ed. 2007, 46, 8050-8053; Angew. Chem. 2007, 119, 8196-8199; b) $\mathrm{H}$. Wang, R. Fröhlich, G. Kehr, G. Erker, Chem. Commun. 2008, 5966-5968; c) K. Chernichenko, M. Nieger, M. Leskelä, T. Repo, Dalton Trans. 2012 41, 9029-9032; d) J. Lam, K. M. Szkop, E. Mosaferi, D. W. Stephan, Chem. Soc. Rev. 2019, 48, 3592-3612.

[13] a) A. E. Ashley, D. O'Hare, Top. Curr. Chem. 2012, 334, 191 -217; b) M.-A. Courtemanche, M.-A. Légaré, L. Maron, F.-G. Fontaine, J. Am. Chem. Soc. 2014, 136, 10708-10717; c) X. Wang, C. Xia, L. Wu, Green Chem. 2018, 20, 5415-5426.

[14] a) R. L. Melen, Angew. Chem. Int. Ed. 2018, 57, 880-882; Angew. Chem. 2018, 130,890-892; b) C. Tang, Q. Liang, A. R. Jupp, T. C. Johnstone R. C. Neu, D. Song, S. Grimme, D. W. Stephan, Angew. Chem. Int. Ed. 2017, 56, 16588-16592; Angew. Chem. 2017, 129, 16815-16819.

[15] J. H. W. LaFortune, A. Trofimova, H. Cummings, S. A. Westcott, D. W. Stephan, Chem. Eur. J. 2019, 25, $12521-12525$.

[16] a) E. Wolf, H. K. Cammenga, Z. Phys. Chem. 1977, 107, 21-38; b) N. Eckardt, H. J. Flammersheim, H. K. Cammenga, J. Therm. Anal. Calorim. 1998, 52, $177-185$.

[17] J. Harada, K. Ogawa, S. Tomoda, Acta Crystallogr. Sect. B 1997, 53, 662 672.

[18] A. Mostad, C. Rømming, Acta Chem. Scand. 1971, 25, $3561-3568$.

[19] A. W. Addison, T. N. Rao, J. Reedjik, J. van Rijn, G. C. Verschoor, J. Chem. Soc. Dalton Trans. 1984, 1349-1356.

[20] R. G. Pearson, J. Am. Chem. Soc. 1963, 85, 3533-3539.

[21] M. Lange, J. C. Tendyck, P. Wegener, A. Hepp, E.-U. Würthwein, W. Uhl, Chem. Eur. J. 2018, 24, 12856-12868.

Manuscript received: October 16, 2020

Accepted manuscript online: December 7, 2020

Version of record online: January 28, 2021 